\title{
MUSEIMÄN GÖRE SIG EJ BESVÄR
}

\section{Mikael Parr}

Personhistoriska museer hör, liksom arbetslivsmuseer, till de museer vars antal ständigt ökat under senare år, både i Sverige och i flera andra västeuropeiska länder. Gemensamma nämnare för de två kategorierna är inriktningen mot samtidshistoria och att många av dem tillkommit tack vare frivilliga krafter, som vanligen gått samman i olika typer av föreningar och sällskap.

Det som i forsta hand skiljer dem àt är att arbetslivsmuseerna uppmärksammar det kollektiva arbetet och människors vardagsliv, medan de personhistoriska museerna ägnas den unika gärningen och enskilda människors historia.

För närvarande finns det 69 personhistoriska museer i Sverige', samt några välbevarade borgarhem uppkallade efter mer eller mindre kända personer eller släkter. Personhistoriska samlingar och utställningar i våra kommunala och statliga
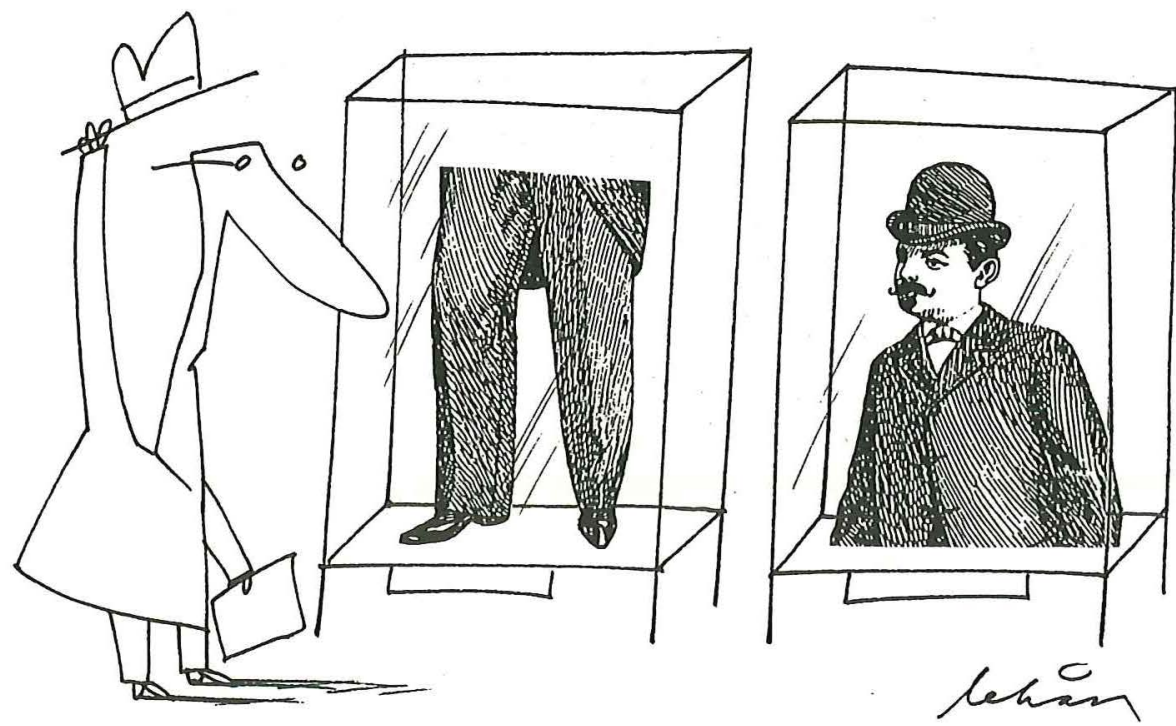
MIKAEL PARR

110 museer ej inräknade, ej heller de slott och herresäten som är öppna för allmänheten.

Liksom flertalet av våra hundratals arbetslivsmuseer och större hembygdsmu- seer så är det endast ett fåtal av de personhistoriska museerna som existerar officiellt, dvs genom statistisk redovisning, offentliga anslag, medlemskap i Svenska

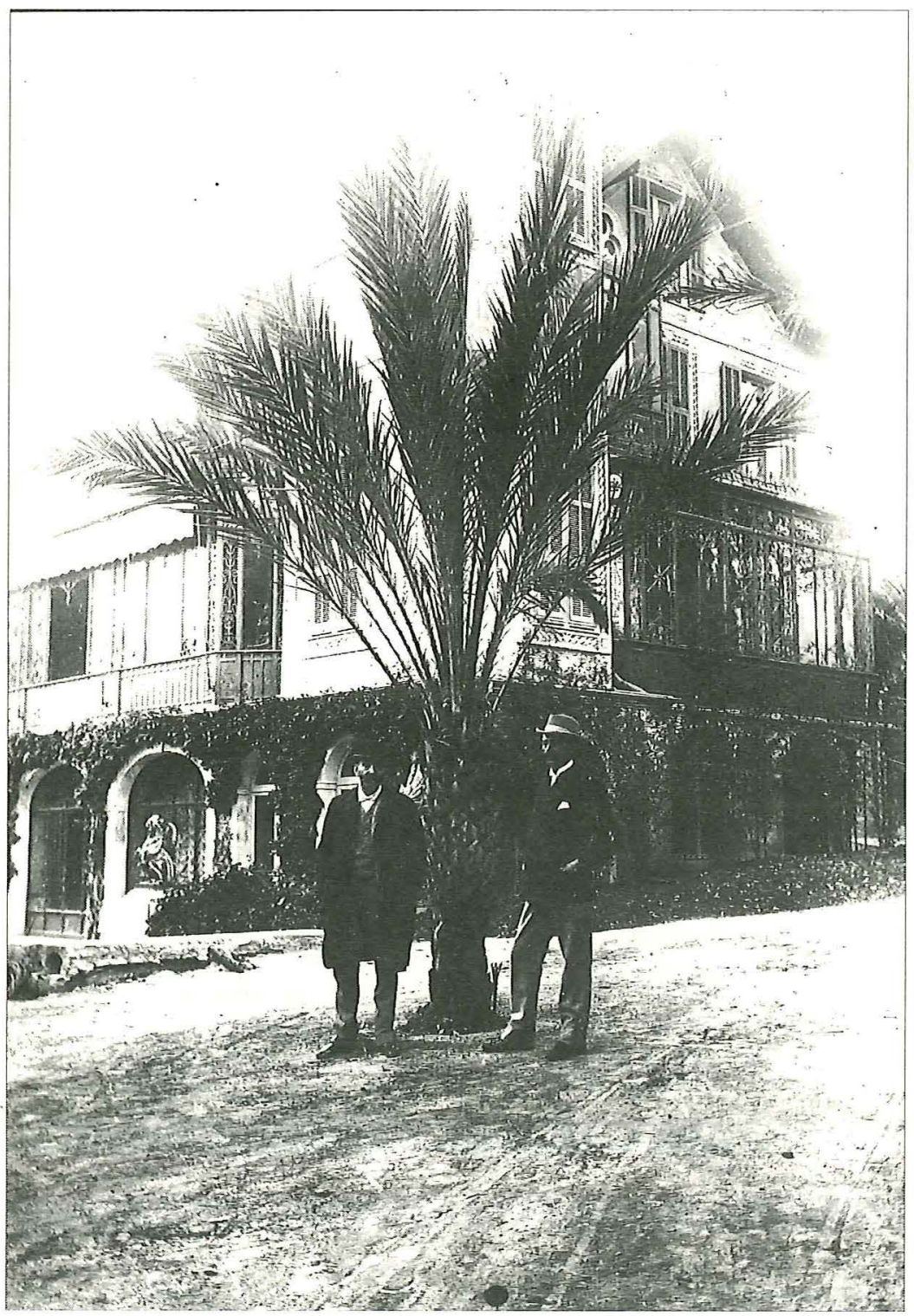

Alfred Nobel och Wilhelm Unge i parken utanfor Alfred Nobels villa i San Remo. Här levde han periodvis under de sista sex åren av sitt liv. Huset är numera museum. Foto: Nobelstiftelsen, Stockholm. 
Museiföreningen etc. I detta fall faktiskt endast en handfull och då främst de som kan rubriceras som konstmuseer eller konsthallar, såsom Aguélimuseet i Sala, Ålgården (Kempesamlingen) i Borås, Millesgården i Stockholm, Zornmuseet i Mora och Waldemarsudde i Stockholm.

Hur gör man då för att få ett eget museum? Om man nu inte råkar ha resurser som grevinnan von Hallwyl ${ }^{2,}$ bör man i första hand tänka på sitt yrkesval. Museibanan är inte att rekommendera. Principen film om film, som glatt tillämpas av flera andra media, är som bekant inte så populär i vår bransch. Som tur är, kanske någon tänker. Advokater, lärare och sjukvårdsbiträden göre sig ej heller besvär. Inte ens skådespelare ${ }^{3}$ och idrottsmän, även om jag läst någonstans att Gunde Svan lär ha ett museum hemma hos sin mamma. Författare eller konstnär kan däremot vara ett mycket bra val.

Om man vill bli tillägnad ett museum är det också en klar fördel om man haft ett hem, framförallt ett barndomshem ${ }^{4}$. Vistelsens längd är av underordnad betydelse.

Med hänsyn till vår jämförelsevis ringa folkmängd är 69 «enmansmuseer» ett relativt stort antal. I Tyskland finns det 139, i Storbritannien 100, i Frankrike 98. Österrike har $14^{5}$.

Hur kommer sig detta? Om man så vill har Sverige hyst ett ovanligt stort antal begåvade och märkvärdiga personligheter. En del kanske drar slutsatsen att det istället är pengar som det funnits gott om. Etablerings- och driftkostnaden är dock förhållandevis låg för flertalet museer av denna typ.

Det kan också vara så att svenskarna är ett folk som gärna hänger sig åt hyllningar och beundran av andra och andras fram- gångar. Något som $\mathrm{i}$ viss mån talar emot dessa förslag till förklaringar, är att drygt hälften av våra personhistoriska museer är tillägnade författare och konstnärer (20, respektive 18). Det tycks vara gärningen, det skapade, inte personen i sig, som varit huvudorsaken vid tillkomsten av många av dessa museer.

Bland författarna kan nämnas Jan Fridegård (med två museer), Gustav Fröding, Moa Martinsson, Selma Lagerlöf och August Strindberg ${ }^{6}$; och inom konstnärsgruppen har vi bl a (utom tidigare nämnda) Bror Hjorts Hus i Uppsala, Carl Larsson-gården i Sundborn, Döderhultarmuseet i Oskarshamn, Carl Eldhs Ateljémuseum i Stockholm, Ljungbergmuseet i Ljungby och Museum Anna Nordlander i Skellefteå. Det sistnämnda för övrigt ett av de senast öppnade (försommaren 1995). En kombination av dessa yrken kan Albert Engström-museerna i Grisslehamn sägas representera.

En grupp konstnärligt arbetande bland vilka förhållandevis få svenskar, till skillnad från flera andra västeuropeer, blivit uppmärksammade genom ett eget museum är kompositörer och musiker. Vi har emellertid sex personer som man skulle kunna föra till denna kategori (eller kanske snarare diktare/musiker): Dan Andersson (två museer), Carl Michael Bellman, Jussi Björling, Joe Hill, JokkmokksJokke och Carl Jularbo?.

Företagsledare och präster har förärats tre museer var $^{8}$ och tre framträdande politiker har fått var sitt museum². Andréemuseet i Gränna är det enda tillägnat en upptäcktsresande.

En grupp som däremot är tämligen välrepresenterad är innovatörer och vetenskapsmän med sammanlagt nio museer. 
MIKAEL PARR

112

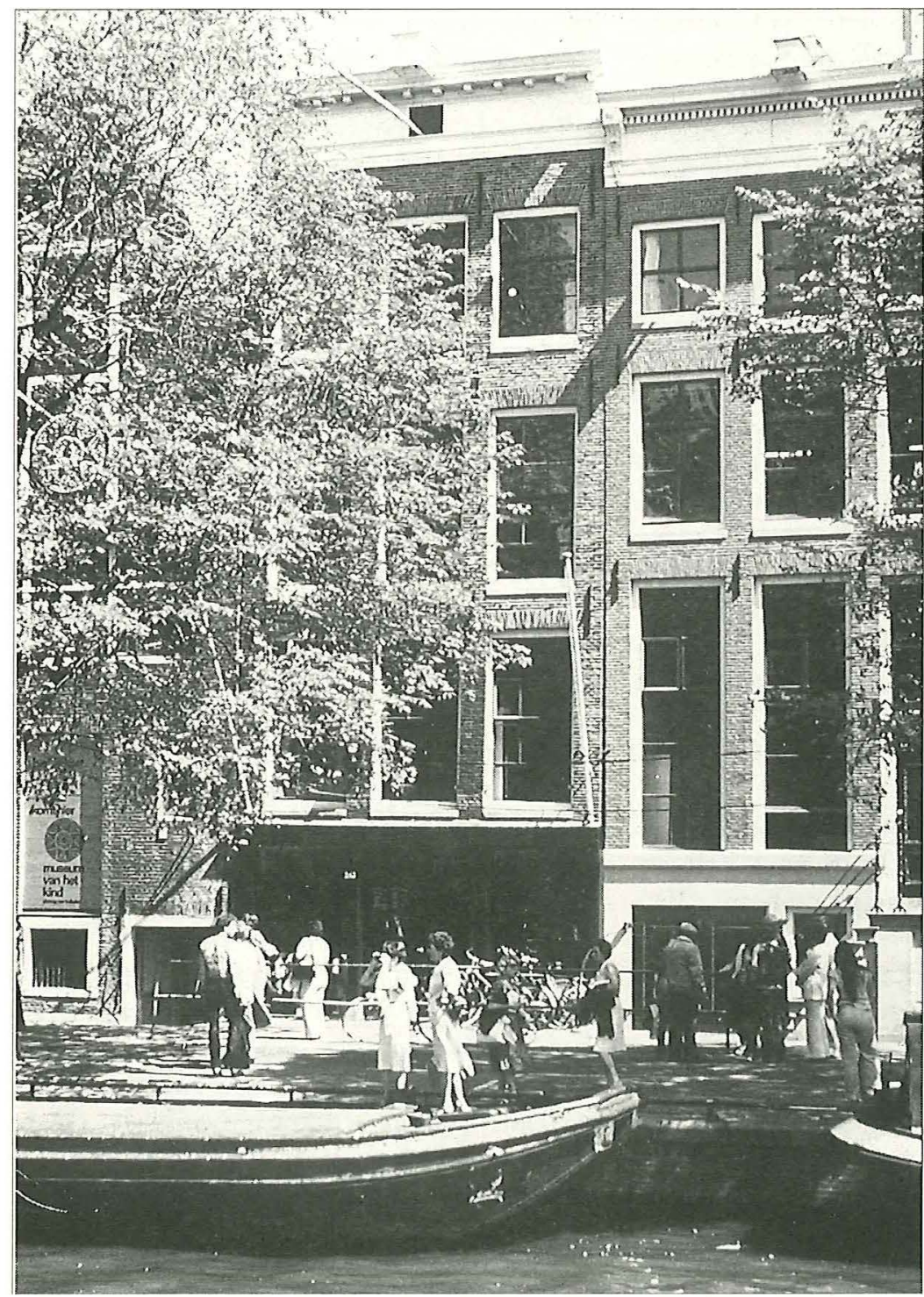

Entrén till Anne Franks hus i Amsterdam. 600.000 besökarelär innebär ett enormt slitage i en autentisk miljö. Anne Frank Stichting planerar nu forr ny entré $m m$ intilliggande fastigheter för att bättre kunna ta emot besökarna. Stiftelsen producerar dessutom vandringsutställningar, böcker och filmer. Den internationella vandringsutställningen "Anne Frank in the World 19291945" har under de senaste tio åren setts av över 5 miljoner människor. En ny version av vandringsutställningen produceras för närvarande.

Foto: AFF/AFS Amsterdam the Netherlands
Jacob Berzelius, Tycho Brahe, Elias Magnus Fries, Alfred Nobel, Cristopher Polhem och Pontus Wikner har var sitt ${ }^{10}$. Carl von Linné leder med tre olika museer (Linnémuseet och Linnés Hammarby i
Uppsala samt Råshult i Älmhult). Alfred Nobel är dock en "coming man". Ett nytt museum planeras av Nobelstiftelsen i Stockholm, om än inte renodlat personhistoriskt. Norska Stortingets nobelkom- 
mitté planerar dessutom ett museum kring fredspriset i Oslo.

Varför dyker det ständigt upp nya personhistoriska museer? Den främsta anledningen, oavsett svenskens eventuella fallenhet för idoldyrkan, är nog att människor lokalt velat hylla och bevara minnet att bygdens stora son eller dotter.

En viktig anledning till att den här formen av museer fortsätter att vara populära besöksmål torde vara, att historien helt enkelt blir intressantare när den personifieras. Till skillnad från den kortfattade och snabba informationen i dagens medier, även i våra utställningar, erbjuder de renodlade personhistoriska museerna besökaren en möjlighet att i lugn och ro fördjupa sig och skapa sig en helhetsbild.

Kenneth Hudson menar att det beror på att de är trevliga utflyktsmål som på en timma kan tillfredsställa ens nyfikenhet kring kändisars personliga vanor. Men att deras främsta tillgång är att de, till skillnad från många populära museer, inte får den genomsnittlige besökaren att känna sig okunnig, outbildad och liten.

Att historien kan beröra och att den blir intressantare om den blir personifierad håller säkert många med om. Det bästa exemplet torde vara Anne Franks Hus. Genom den unga flickans dagbok och hennes familjs gömställe undan nazisterna, som nu är museum, kommer historien nära. 1930- och 40-talets pogromer blir kanske inte fattbara, men vi kan förhoppningsvis lära oss något. Anne Franks Hus i Amsterdam lockar årligen mer än 600.000 besökare.

Det kanske är så att vi, av flera olika anledningar, borde göra oss besvär.
SUMMARY

Curators should not take the trouble...

Sweden has a comparatively large number of museums honouring famous people, considering the size of its population. Of those museums, 69 in all, 20 are devoted to authors and 18 to artists. In contrast to similar museums in Western Europe, only a few Swedish museums celebrate composers and musicians, which is also true of politicians and churchmen. The latter categories seem also to be rather few in Western (as opposed to Eastern) Europe. Innovators and scientists are the subject of nine museums - Carolus Linnæus of no less than three. Several museums honouring Alfred Nobel are being planned. The number of 'biographic' museums is rising. The most important reason seems to be a local interest in celebrating a famous person born in the locality. Furthermore they are popular visiting places. History seems to gain a particular interest when it is embodied in an individual life-story. Anne Frank's House in Amsterdam is the outstanding example of this. A museum specifically devoted to Nazi atrocities and the persecution of Jews would not presumably attract as many visitors, numbering 600,000 in the case of Anne Frank's House.

\section{NOTER}

1. Förteckning kan erhållas av artikelförfattaren.

2. Hallwylska museet, Stockholm.

3. Med undantag av Fridolf Rhudin-museet $\mathrm{i}$

Munkfors, ett Nils Poppe-museum (på

Fredriksdals Friluftsmuseum i Helsingborg) och ett Garbo-museum, som nyligen har öppnats på PUB i Stockholm.

4. 11 av de 69 museerna är med säkerhet barndomshem.

5. Hudson, Kenneth: Museums Journal feb 1995 , sid 21.

6. Jan Fridegård-museet, Övergarn, Jan Fridegårds 
MIKAEL PARR

114 minnesstuga, Enköping, Alsters herrgård utanför Karlstad, Moa Martinsson-torpet i Sorunda, Mårbacka i Sunne och Strindbergsmuseet i Stockholm.

7. Loussastugan i Grangärde, Dan Andersson museum i Ludvika, Bellmanmuseet i Stockholm, Jussi Björling museet i Borlänge, Joe Hill-museet i Gävle, Jokkmokks Jokkes Museum i Vuollerim och Carl Jularbo Museum i Avesta.

8. Hjalmar Lundbohmsgården i Kiruna, Lars Magnus Ericssons minnesgård i Värmskog, JP Johanssons Museum i Enköping. Bishop Hillmuseet i Enköping, Læstadie pörte i Pajala och Söderblomsgården i Trönö.

9. Dag Hammarskjöids Backåkra, Löderup, Erlandergården i Ransäter och Per Albin Hansson-museet i Malmö.

10. Berzeliusmuseet i Stockholm, Tycho Brahe museet på Ven, Friesmuseet i Hylte, Björkborn i Karlskoga, Stjernsunds bruk (Polhems-gården) vilket ingår i Husbyringen ekomuseum och Pontus Wikner museerna i Munkedal.

Illustrationen på sid 107 är utförd av Lars-Erik Håkansson (lehån).

\section{LITTERATUR}

af Geijerstam, Jan: Arbetets historia i Sverige - En guidebok till museer och miljöer. Oskarshamn 1990.

Hudson, Kenneth: Museums Journal. Feb 1995. Lagerkvist, Bengt: Följ med! Bengt Lagerkvist på Konstresa genom Sverige. Danmark 1995.

Museer i Sverige. Nyström, Bengt: red. Borås 1990. Museiguiden - Vägledning till svenska museer. Nyström, Bengt: red. Kristianstad 1984.

Upptäcksresan 1993. Blomberg, Barbro: red. Falkenberg 1993.

Upptäcksresan 1994. Holkers, Märta: red. Helsingborg 1994.
Upptäcksresan 1995. Holkers, Märta: red. Helsingborg 1995.

\section{OTRYCKTA KÄLLOR}

Gillert, Arne: Anne Frank Stichting, Holland. Swedelines turistdatabas «SverigeBanken», okt 1995.

Walnes, Gillian: Anne Frank Educational Trust, England.

Westlund, Jan: 646 museer och samlingar med anknytning till yrkes- och arbetsliv. Arbetets museum 1988.

Mikael Parr är utställningschef vid Arbetets museum, Norrköping.

Adr: Arbetets museum, Laxholmen, S-602 21

Norrköping.

Fax +46-11 182290 . 